\title{
Isolation and Molecular Identification of Trichophyton rubrum var. raubitschekii from the Infant Groin.
}

\author{
Hana K. Maikhan ${ }^{\text {a }}$, Khalid A. Habeb ${ }^{b}$, Ahmed A.Suleiman ${ }^{c}$.
}

\begin{abstract}
Five clinical isolates of Trichophyton rubrum isolated from patients with dermatophytosis in the Dermatology unit of the General Hospital in Kalar distric/Sulaimani province/North region of Iraq. The isolates were identified according to the conventional laboratory methods and molecular methods, one of these strains was isolated from the groin of an infant with one year old and identifies as Trichophyton rubrum var. raubitschekii. This variety characterized by the production of cottony to a velvety colony. The front of the colony appeared brown color with brownish pigmentation at the reverse. Slide examination revealed numerous cylindrical shaped microconidia and few longer macroconidia. Molecular identification was conducted according to the conventional PCR by using set primers ITS1 and ITS4 and resulted in PCR product about 690bp. PCR-RFLP by using BstN1 digestion enzyme revealed three pattern bands $380,180,100 \mathrm{bp}$. While sequencing of the ITS region revealed high similarity with that of a number of uncultured endocytic fungus clone.
\end{abstract}

Key words: Trichophyton rubrum var. raubitschekii; ITS, PCR, RFLP, Sequencing.

\section{Introduction}

Trichophyton rubrum is the major causative agent of dermatophytosis all over the world which includes tinea pedis, tinea corporis and tinea capitis (Gräser et al., 2000). Different species of dermatophytes have similar signs which are difficult to distinguish during clinical examination. In vitro culturing of dermatophytes is sensitive, specific; but requires long incubation period represents a drawback for diagnosis and treatment. As well as microscopic examination to describe micro and macroconidia provides rapid identification and gives sensitivity about $85 \%$ to detect the fungal pathogen. The amplification of DNA by PCR in the recent years enhanced the phylogenic determination of dermatophyte species (Liu et al., 2002). The phenotypic variants of Trichophyton rubrum did not revealed DNA variability (Gräser et al., 1999). Trichophyton rubrum var. raubitschekii belonging to 
Trichophyton rubrum complex and distinguished byurease positive and the production of profuse microconidia in the culture. It is isolated classically from patients with tinea cruris and tinea corporis in Africa and South-east Asia (Arabatzis et al., 2005). This strain differs from the common strains of T.rubrum morphologically, clinically and physiologically despite homogeneity (Llkit et al., 2011). The present study was aimed to molecular identification of Trichophyton rubrum var. raubitschekii and comparison between the sequencing of the ITS gene in the locally isolate which was identified in the study and the recorded isolates according to the data that provided by NCBI.

\section{Materials and Methods}

\section{The Subject Study}

Twenty clinical specimens included infected nail, hair and skin scraping collected from suspected patients with tinea infection (tinea pedis, tinea cruris and tinea corporis) under the supervision of specialized physicians and attended to the Dermatology Department of the General Hospital in Kalar district/Sulaimani Province. Specimens collected during the period of three months from September to the end of November 2016. The specimens (nail and skin scraping) were collected aseptically into disposable containers, labeled and transported on time to the research laboratory of Biology Department at College of Education / University of Garmian, for mycological examination.

\section{Identification of Dermatophytes}

Each specimen was divided into two parts, one of them for direct microscopic examination and the other part for culturing. Microscopic examination by $\mathrm{KOH}$ was performed to show the filamentous hyphae and arthrospores of dermatophytes. The second part of the specimens were cultivated on PDA and SDACC incubated at $25{ }^{\circ} \mathrm{C}$ for 21 dyes and examined at regular intervals (each three days) (Rippon, 1988). The isolates were identified by cultural characteristic (colonial morphology) and fungal species were diagnosed by direct mount examination with was carried out by Lactophenol Cotton Blue (LPCB) (Forobes et al., 1998). Biochemical tests were performed by urease test, growth on rice grain and hair perforation test. The fungal genomic DNA was extracted from the fungal colonies by using OMEGA Fungal DNA Mini Kit $\backslash$ (USA). Molecular identification was carried out by speciesspecific PCR by amplification of the internal transcript spacer (ITS) gene of rDNA in dermatophyte species. The amplification was carried out by using one pair of primers symbolized ITS1and ITS4 as forward primer and reverse primer respectively (Refai et al., 
2013). PCR was performed in $25 \mu \mathrm{L}$ final reaction volume, of PCR reaction mixture containing which consisted of: $12.5 \mu \mathrm{L}$ of Master Mix (X2), $2 \mu \mathrm{L}$ of DNA template, $9.5 \mu \mathrm{L}$ of dDeionized water and $0.5 \mu \mathrm{L}$ for from each primer (forward primer ITS1 and reverse primer ITS 4). The PCR conditions were made according to Ghojoghi, et al., (2015) included: Initial denaturation at $95{ }^{\circ} \mathrm{C}$ for one minute, followed by 35 cycles of denaturation at $95{ }^{\circ} \mathrm{C}$ for 30 seconds., annealing at $55^{\circ} \mathrm{C}$ for 1 minute, extension at $72{ }^{\circ} \mathrm{C}$ for 2 minutes and final extension at $72{ }^{\circ} \mathrm{C}$ for 5 minutes. The amplified DNA fragment was visualized in $1.5 \%$ agarose gel. PCR-RFLP analysis was conducted by using the BstN1 restriction enzyme (BioLab, UK) according to the protocol provided by the manufacturer. The PCR products were sequenced in South Korea (Macrogene lab $\backslash$ as Standard Sequencing Service).

\section{Results}

Among the twenty clinical specimens were isolated from patients with dermatophytosis, five of them identified as Trichophyton rubrum by conventional macroscopic, microscopic, and biochemical methods. The cultural characteristic of isolates has cottony to velvety colonies with white color at the surface and wine to brown pigmentation at the reverse. The microscopical method with $10 \% \mathrm{KOH}$ shows fungal hyphae, numerous cylindrical, pyriform to oval shape microconidia born singly or along the hyphae and a large, smooth, multi septet and cylindrical shape macroconidia .

Out of five clinical isolates only one (20\%) of them being from the groin of infant with one year old and identifies as Trichophyton rubrum var. raubitschekii which characterized by hardly furrowed with suede-like surface and raised at the center with faint pink color on the surface and dark brown at the reverse surrounded by halo with yellow color on SDADD (Fig 1). On PDA the front of the colony appeared with brown color and brownish pigmentation at the reverse (Fig 2). Microscopically, slide examination revealed numerous small rounded microconidia born along short branch or pedicles of hyphae (Fig 3A). Numerous cylindrical shaped macroconidia and few longer macroconidia were seen (Fig 3B and C). This isolate differs from the other clinical isolates of T.rubrum which was urease positive.

Molecular identification by species-specific PCR conducted by amplification of the ITS region on the ribosomal DNA by using a set of universal primers ITS1 and ITS4. Amplification of the ITS region was visualized in $1.5 \%$ agarose gel electrophoresis. 
Amplicon size determined by comparison with 100 bp DNA ladder. A band size of 690bp confirms a positive result.

PCR-RFLP by BstN1 restriction enzyme showed similarity with the results of PCRRFLP of the rDNA in the other isolates of T.rubrum and revealed three patterns 380, 180 and $100 \mathrm{bp}$ during the electrophoresis in 3\% agarose gel (Fig 4). Sequencing of the ITS partial gene in the rDNA of the variety Trichophyton rubrum var. raubitschekii was differed completely from that of T.rubrum and showed high similarity to that of Phoma spp. and uncultured endocytic fungus (Fig 5).



Figure (1): Colonial morphology of Trichophyton rubrum var. raubitschekii after three weeks of incubation at $25^{\circ} \mathrm{C}$ on SDACC.

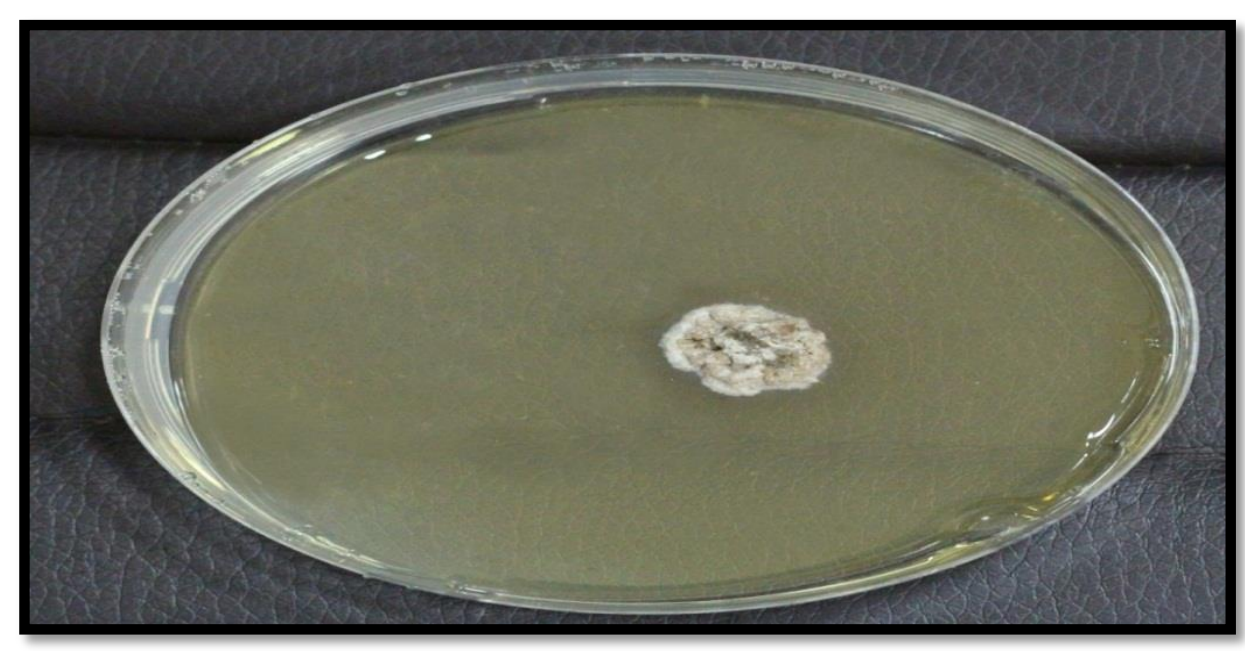

Figure (2): Colonial morphology of Trichophyton rubrum var. raubitschekii on PDA at $25{ }^{\circ} \mathrm{C}$ after one week of incubation. 


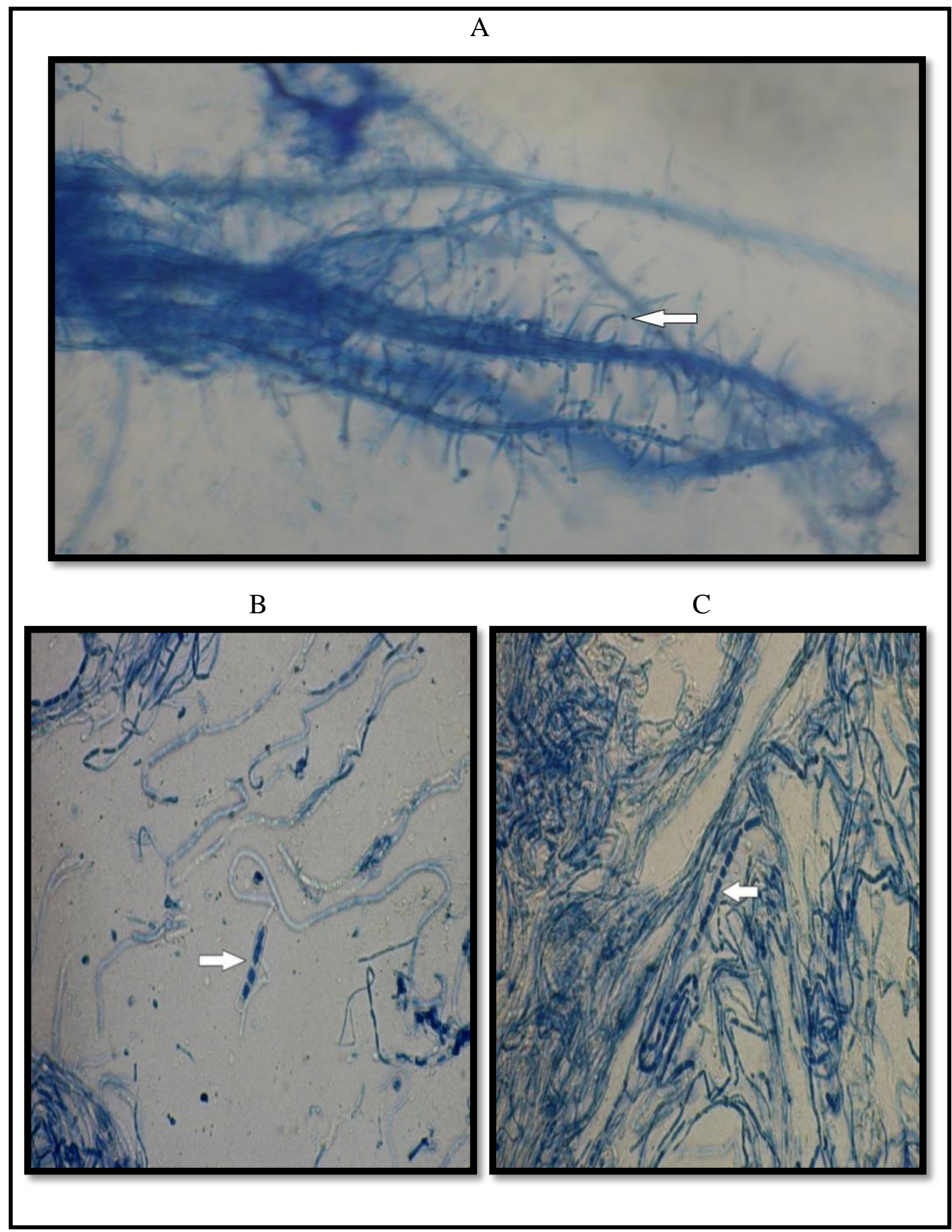

Figure (3): Microscopical morphology of Trichophyton rubrum var. raubitschekii colony mounted with LPCB stain showing: A) Microconidia bearing on branched hyphae. B) Cylindrical shaped macroconidia. C) Longer macroconidia (40X). 


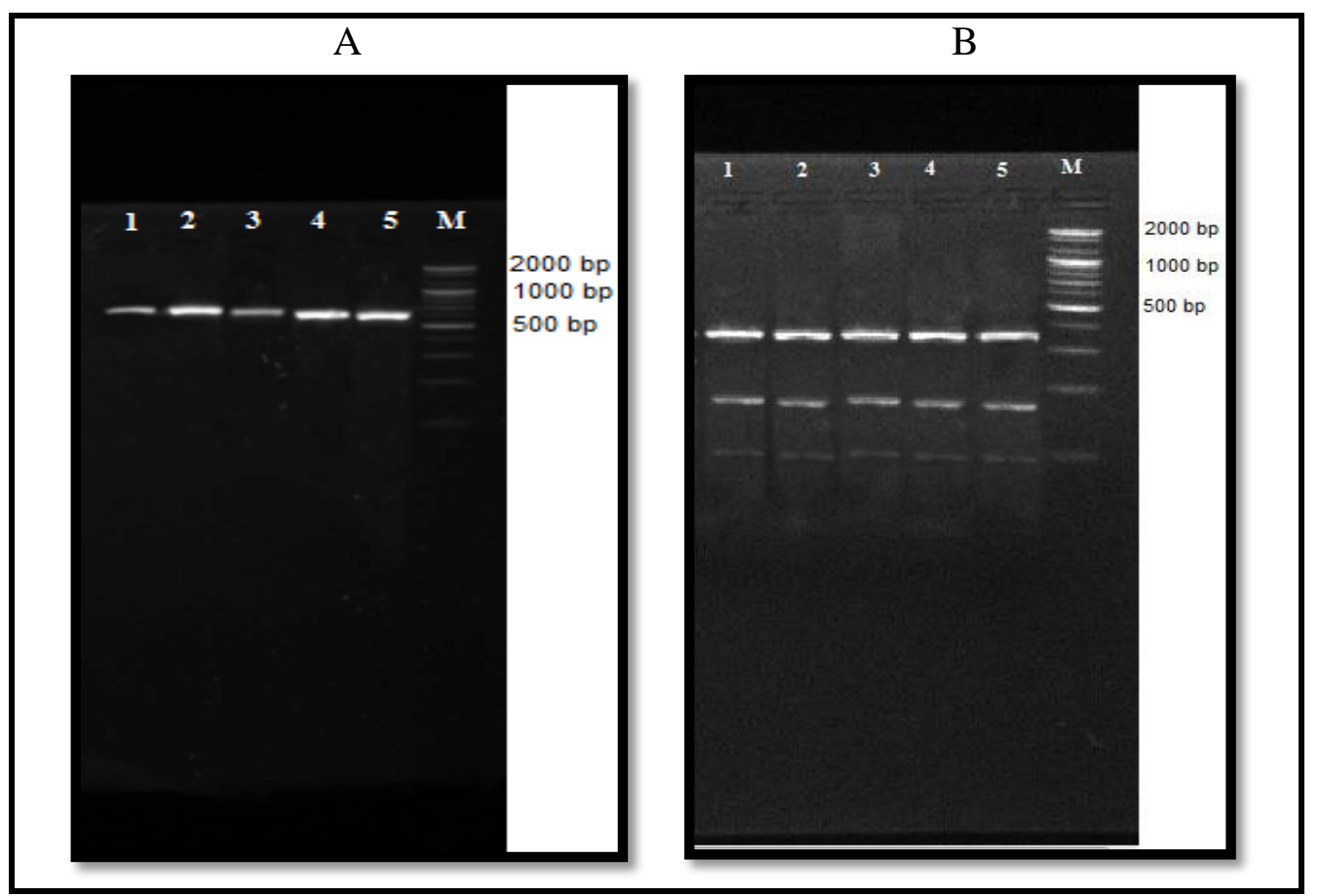

Figure (4): (A) Amplification of a 690bp fragment of ITS region in Ttichophyton rubrum. Lane: M, 100bp DNA Marker; lanes 1 to 5, PCR amplification of ITS region. (B) PCR-RFLP of ITS region in Trichophyton rubrum. Lane: M, 100bp DNA Marker; lanes 1 to 5, restriction analysis with BstNI (380bp, 180bp, and 100bp). 
Fungal sp. P5N27 internal transcribed spacer 1, partial sequence; 5.8S ribosomal RNA gene and internal transcribed spacer 2, complete sequence; and 28S ribosomal RNA gene, partial sequence

Sequence ID: gi|573864655|gb|KF735014.1|

\section{Alignment statistics for match \#1}

Score

Expect

Identities

Gaps

Strand

797 bits(431)

0.0

463/479(97\%)

0/479(0\%)

Plus/Plus

Query 5 ACCCAGAGTTGTGAGCTTTGCCTGCTATCTCTTACCCATGTCTTTTGAGTACCTTCGTTT 64

||| |||||||| |||||||||||||||||||||||||||||||||||||||||||||

Sbjet 14 ACCTAGAGTTGTAGGCTTTGCCTGCTATCTCTTACCCATGTCTTTTGAGTACCTTCGTTT 73

Query 65 CCTCGGCGGGTCCGCCCGCCGATTGGACAATTTAAACCATTTGCAGTTGCAATCAGCGTC 124 ||||||||||||||||||||||||||||||||||||||||||||||||||||||||||

Sbjet 74 CCTCGGCGGGTCCGCCCGCCGATTGGACAATTTAAACCATTTGCAGTTGCAATCAGCGTC 133

Query 125 TGAAAAAACTTAATAGTTACAACTTTCAACAACGGATCTCTTGGTTCTGGCATCGATGAA 184 |||||||||||||||||||||||||||||||||||||||||||||||||||||||||||

Sbjct 134 TGAAAAAACTTAATAGTTACAACTTTCAACAACGGATCTCTTGGTTCTGGCATCGATGAA 193

Query 185 GAACGCAGCGAAATGCGATAAGTAGTGTGAATTGCAGAATTCAGTGAATCATCGAATCTT 244 |||||||||||||||||||||||||||||||||||||||||||||||||||||||||||

Sbjet 194 GAACGCAGCGAAATGCGATAAGTAGTGTGAATTGCAGAATTCAGTGAATCATCGAATCTT 253

Query 245 TGAACGCACATTGCGCCCCTTGGTATTCCATGGGGCATGCCTGTTCGAGCGTCATTTGTA 304 |||||||||||||||||||||||||||||||||||||||||||||||||||||||||||

Sbjet 254 TGAACGCACATTGCGCCCCTTGGTATTCCATGGGGCATGCCTGTTCGAGCGTCATTTGTA 313

Query 305 CCTTCAAGCTCTGCTTGGTGTTGGGTGTTTGTCTCGCCTCTGCGAGTAAACTCGCCTCAA 364

|||||||||| ||||||||||||||||||||||||||||||| ||| |||||||||||

Sbjct 314 CCTTCAAGCTTTGCTTGGTGTTGGGTGTTTGTCTCGCCTCTGCGTGTAGACTCGCCTCAA 373

Query 365 AACAATTGGCAGCCGGCGTATTGATTTCAGATCGCACTACATCTCGCGCTTTGCACTCAG 424

||||||||||||||||||||||||||| || |||| ||||||||||||||||||||||

Sbjct 374 AACAATTGGCAGCCGGCGTATTGATTTCGGAGCGCAGTACATCTCGCGCTTTGCACTCAG 433

Query 425 AAAGACGACGTCCATAAGTAAATTTTGACACTCTTGACATCGGATCAAGTACGGATACC 483

|| ||||||||||| ||||| ||||| ||||||||||| |||||||| ||| |||||||

Sbjct 434 AACGACGACGTCCAAAAGTACATTTTTACACTCTTGACCTCGGATCAGGTAGGGATACC 492

Figure (5): Sequencing of ITS region in Trichophyton rubrum var. raubitschekii 


\section{Discussion}

Trichophyton rubrum is an anthropophilic species and can be transmitted easily from infected person to another during simulation and using clothes. Venkatesan et al., (2007) explained that tinea corporis was the most common type of dermatophytosis and T. rubrum was the major causative agent among dermatophytes in India. According to the morphological characters of the fungal colon on SDACC, two types of T. rubrum were identified and these included downy and granular types. Out of five clinical isolates of T. rubrum, three isolates were identified as downy types, one isolate was granular type and the other isolate was identified as T. rubrum var. raubitschekii. Morphologically, this variant differs from the other variants by producing reddish brown colony with hardly, glabrous furrowed suede-like texture. Microscopically, there are numerous microconidia carried on short branched hyphae, cylindrical macroconidia and few longer macroconidia with the ability to produce urease enzyme (urease positive) which is the important character for the identification process (Ellis et al., 2007). According to the molecular approaches which conducted by species-specific PCR revealed that the amplification of the ITS gene in the T. rubrum var. raubitschekii by PCR which result 690bp product, while the PCR-RFLP analysis by using single restriction enzyme BstN1 provides three bands 380m 180 and 100bp and these results were similar with the results of the molecular identification of the other isolates of T.rubrum in the present study. The databases of ITS sequence of the variant T. rubrum var. raubitschekii (repeated three times) alignment and later calculated the similarity score between the query sequence and reference sequence by using BLAST sequence analysis tool "http:www.ncbi.nlm.govไBLAST" from the National Center for Biotechnology Information. According to the sequence of ITS region in rDNA by using two universal primers ITS1 and ITS4 then alignment in NCBI this variant showed high proportions in the similarity with uncultured fungus reached to $97 \%$ and this variance between the results of this study with another study may be due to mistake in the identification process, technical errors during PCR amplification, a mutation in the ITS regions or mistakes in the sequencing process. So to make sure the diagnosis is accurate, we need to amplify other genes and re-analyze them by gene sequencing.

\section{References}

- Arabatzis, M.; Velegraki, A.; Kantardjiev, T.; Stavrakieva, V.; Rigopoulos, D. and Katsambas, A. (2005). First report on autochthonous urease positive Tricophyton rubrum from South east Europe. Br. J. Dermatol., 153 (1): 178 - 82. 
•Ellis, D.; Davis, S.; Alexiou, H.; Handkw, R. and Bartley, R. (2007). Description of Medical Fungi. 2nd edition. Adelaid. Australia.

•Forobes, B.A.; Sahm, D.F. and Weissfeld, A.C. (1998). Dignostic Microbiology. 10th ed., Mosby, Inc. London.

- Ghojoghi, A.; Falahati, M.; Paghehm A.S.; Abastabar, M.; Ghasemi, Z.; Ansari, S.; Farahyar, S. and Roudbary, M. (2015). Molecular Identification of Epidemiological Aspect of Dermatophytosis in Tehran, Iran. J. Research in Molecular Medicine, 3:11-16.

- Gräser, Y., Kuijpers, A. F., Presber, W. and De Hoog, G. S. (2000). Molecular taxonomy of the Trichophyton rubrum complex. J Clin Microbiol 38, 3329-3336.

• Gräser, Y.; El Fari, M.; Vilgalys, R.; Kuijpers, A. F.; De Hoog, G.S. Preber, W. and Tietz, H. (1999). Phylogeny and Taxonomy of the family Arthrodermaceae (dermatophytes) using sequence analysis of the ribosomal ITS region. Med Mycol, 37:105-114.

- Ilkit, M.; Saracl, MA. and Yukse, T.(2011). Trichophyton rubrum with the 'raubitschekii' morphotype: the first report from Turkey. Mycopathologia, 171(2):119-122.

•Liu, D.; Pearce, L. Lilley, G.; Coloe, S.; Baird, R. and Pedersen J. (2002). PCR identification of dermatophyte fungi Trichophyton rubrum, T. soudanense and T. gourvilii. J Med Microbiol. 51(2):117-22.

-Refai, M.; El-Yazid, H. A. and Al- Hariri, M. (2013). Monograf on Dermatophytes. A guide for isolation and identification of dermatophytes, diseases and treatment. Cairo. Egypt.

-Rippon, J. W. (1988). Medical Mycology. The pathogenic fungi and pathogenic Actinomycetes. W.B. Saunders. Philadelphia, 3rd. ed.196. USA.

-Venkatesan, G.; Singh, A.J.A.; Murugesan, A.G.; Janaki, C. and Shankar, S.G. (2007).Trichophyton rubrum - the predominant aetiological agent in human dermatophytosis in Chennai, India. Afr J Microbiol Res, 1(1):9-12. 